\title{
A Program Aimed Towards the Struggling Science Teachers of English Language Learners: A Proposition
}

\author{
Faatimah M. Murad \\ Simon Fraser University
}

\begin{abstract}
Increasing intakes of English Language Learners in British Columbia's education system brought a wave of unforeseen challenges; with teachers insufficiently equipped to face this rapidly growing student demographic, and these students who similarly are undergoing challenges of their own. This research article explores some of these challenges while researching current systems set in place to minimize the struggles teachers report, and ultimately proposes a new and unique program that is built on a more supportive educational theoretical framework. A specific focus is drawn on the ELL science teachers' struggles to modify content so as to maintain its rigor and lessen the language demands, while another is their struggle to employ a culturally responsive pedagogy in their practice. The findings show much of the BC Ministry of Education's approaches to be centered around the following: reminders of roles and responsibilities upon teachers and their respective school districts, a select number of workshops that provide teachers with a multitude of strategies, and the sponsorship of outside sources that provide a deeper more prescribed set of strategies. The intention of this article is to propose a program that uses a number of theoretical frameworks (i.e. Vygotskian perspective, Cummins' (1983) language model, Tylerian Objectives-based approach) to ensure its success. Using activity theory with a Vygotskian framework including the cultural historical perspective, and a Tylerian objectives-based approach, a dual-purpose program is designed.
\end{abstract}

Keywords: ELL, ELL science teacher challenges, ELL workshops 


\section{A Program Aimed Towards the Struggling Science Teachers of English Language Learners: A Proposition}

With the numbers of English Language Learner (ELL) students on the rise in the Canadian province of British Columbia; most recent statistics reveal of the 66,285 ELL students enrolled in British Columbia's school system, 62,801 are in the public-school system (BC Ministry of Education, 2017). The BC Ministry of Education (2017) also reports that of the total current elementary students, $17 \%$ of them are ELLs. The rapidly increasing ELL student population accessing the system raises questions about the current status of the curriculum and the forms of support programs that are set in place for teachers of this student demographic. Reports indicate direct and indirect connections between challenges faced by ELL students and their teachers, especially with culturally relevant teaching (Brown \& Crippen, 2016; Roekel, 2008). Researchers acknowledge supporting the ELLs within a classroom is not independent of supporting their teachers through appropriate instructional programs (Han \& Cheng, 2011). These studies focus on linguistic, academic, and cognitive supports for students, and emphasize the need of appropriate educational programs for teachers of the ELL student demographic (Han \& Cheng, 2011). This research article aims to explore some of the challenges faced by ELL science teachers and students in the public-school system, the specific challenges that will be discussed relate to the students' cognitive academic language development, and their sociocultural aspect of learning. As for the ELL science teacher, two major challenges are analyzed, their ability to modify science curriculum for the ELL while maintaining its vigor and their ability to practice culturally responsive pedagogy. I then analyze the support systems that are in place to assist these educators in the Lower Mainland of British Columbia, and use this to propose a program that will better address the needs of both teacher and student, with respect to the BC Science Curriculum.

In efforts to tackle each of the challenges faced by the students and teachers, the respective theoretical frameworks developed to understand these challenges are later mentioned. These references, attributed to prominent educational theorists, are made to shed light on the use of theoretical and practical aids to inform and further develop a teacher's practice (Casale, 2004). The conclusive proposed program employs the cultural-historical activity theory (CHAT) through a Vygotskian perspective while incorporating elements of a Tylerian objectives-based approach.

\section{Literature Review}

Being empirically based, reliable and tentative, scientific knowledge is a product of observation, inferences, and creative thinking, it is dynamic in its multiple forms and methods of development (Burton, 2013). The BC Science Curriculum, still in reform for those in grades 10-12, specifies core competencies and big ideas which students are expected to understand and acquire over the course of their studies (BC Curriculum, 2017). The core competencies address three areas of student development: communication, thinking, personal and social, while the big ideas, depending on the science level, range from three to four content derived concepts that a student is expected to learn in that science level (BC Curriculum, 2017). The previous curriculum documents provided Prescribed Learning Outcomes that were more rigid in nature and 
followed a "top-down" method of delivery (Kuehn, 2016). Contrary to the old format, the new curriculum follows a "bottom-up" design that promotes educator autonomy and respects their creativity (Kuehn, 2016). This change also emphasizes the importance of the teacher's background and strengths, their ability to reflect students' reality in the topics and approaches while linking community and global aspects of that reality (Kuehn, 2016). Regarding science instruction, Abd-El-Khalick, Bell, and Lederman (1998) believe it is helpful and beneficial to provide preservice teachers with a guiding conceptual framework within science method courses; it would enable them to further develop their conceptual understanding of the NOS and enable their students to learn of the history of this subject area, if the teacher desired to take this approach (Abd-ElKhalick, Bell, \& Lederman, 1998). Research studies reveal the benefits teachers find in developing their own understandings of the conceptual frameworks within science and NOS, they report improvements in their lesson plans, abilities to enable students to reflect on conceptual understandings and create more relevant connections to students' reality (Burton, 2013). The importance of drawing such connections with the English Language Learner is amplified as it proves relevant to the challenges they face in the sociocultural domain; their lived experiences "can serve as intellectual resources for academic learning" (Lee \& Buxton, 2013, p.40). The link between teachers, learners, and ELL students is evident based on the findings of studies employing qualitative designs; these findings report improvements in science discourse when teachers are more aware of their student demographic and aim to draw explicit connections with student backgrounds (Verdugo \& Flores, 2007).

\section{Challenges and Support Systems for the ELL}

Correspondingly, in exploring the challenges faced by ELLs, an Ontario-based research study uncovered three areas in which students face challenges: "cognitive academic language development, large-scale high-stake assessments, and sociocultural aspects of learning" (Han \& Cheng, 2011, p.4). Other challenges were associated with acquiring cultural capital and metaphoric competence (Roessingh, Kover, \& Watt, 2005). In response to the latter, the ELL Standards Committee (2001) creating a curriculum that focuses on three language domains of reading, writing and oral expression, international students face challenges when they are required to learn academic concepts built on words that have interchangeable meanings (ELL, 2001; Manavathu \& Zhou, 2012). One example of the latter is in the word "charge"; depending on the context, there are multiple definitions: to attack, a form of cost, accumulation of a force, or the electric charge held on an ion (Webster, 2017). The cognitive academic language development challenges faced by ELLs are also on account of the complex nature of available texts and instructional materials differing from everyday language and narrative texts; the use of technical and complex vocabulary, metaphors and pronouns, and the scarcity of textbooks that incorporate ESL materials (Fang, 2006; Manavathu \& Zhou, 2012). The Cognitive Academic Language Learning Approach (CALLA), is also used as a model in the more linguistically diverse classroom; students are exposed to "high-priority content topics [i.e. Science], academic language development based on the content, and explicit instruction in learning strategies that can help students understand and remember both the content and the language" (Chamot \& O'Malley, 1996, p. 263). This model relies heavily on the language learner's ability to select information from the environment and 
draw connections to their own understandings, a heavily reflective process that encourages the use of English rather than their native languages as often as possible (Chamot \& O’Malley, 1996; Lee, 1997).

The Ministry of Education (2017) states their policy is "to assist students to become proficient in English, to develop both intellectually and as citizens, and to achieve the expected learning outcomes of the provincial curriculum". Updated online resources continue to reference the ELL Standards (2013), where much of the international student curriculum focuses on language acquisition rather than subject matter and basic conceptual understanding (Mollaei \& Rahnama, 2012). To support the ELL in the science classroom, many studies suggest a heavy reliance on hands-on activities that initiate direct student engagement and delay the formal instruction of content vocabulary until after such experiences (Settlage, Madsen, \& Rustad, 2005). In their most recently updated guide for supporting the ELL, the BC Ministry of Education (2015) states "[t]here is no such thing as a typical English Language Learner [...]. Some students require additional support, but not all require the same type of support" (p.28). Instead of having a guide for this student demographic, the BC Ministry of Education formulated policies and guidelines regarding the ELL, guidelines for classroom teachers, and guidelines for ELL specialists. Each of these resources reiterate policies, roles and responsibilities of school districts, schools, teachers, and specialists in determining the level of support their ELL students require. The latter is achieved through the provision of an English Language Learning Instructional Support Plan Overview tool; this tool contains a list of outcomes and achievements that enable an ELL Specialist to assess students individually and place them in the best-fit category (BC Ministry of Education, 2015). Under the School Act 168(2)(a) these students are identified and reported annually to the BC Ministry of education where they will be eligible to receive support in the subject area of interest (School Act, 2016). The available supports would include the eligibility to work with an ELL Specialist, although no specific BC Ministry of Education documents for the ELL Student exist due to the expectation that "support levels will diminish as students progress successfully in a fully integrated program" and that "[services] should be adjusted on the basis of an ongoing review of student performance" (BC Government, 2012). According to the English Language Learning Policy and Guidelines, it is expected these students follow the provincial curriculum plan as all other students would, however it is recognized their assessment and ability to demonstrate their learning would differ from that of other students (ELL, 2011). The above-mentioned document also emphasizes the school's responsibility in adapting the instructional methods and assessment tools to meet their needs and allow them to demonstrate their acquirement of content understanding (ELL, 2011).

\section{Challenges and Support Systems for the Science Teacher}

In researching about challenges faced by science educators working with the ELL student demographic, the increased intake of ELLs adds much responsibility onto the teachers by requiring additional preparatory steps on their part and their own time (Bunch, 2010; Lucas, Villegas, \& Freedson-Gonzalez, 2008). Adding to the complexity, "teacher education programs often reinforce their existing biases" by attributing low achievement scores to student deficits rather than a lack of proper student support 
systems (Buck et al., 2005, p. 1014). Studies report this deficit discourse reinforces the false and unproven notion that English language proficiency is the only cause of an "achievement gap", which results in ELL programs that support a typical narrative of "English is all that matters" (Shapiro, 2014, p. 387). Moving away from the deficit ideology and recognizing the importance of providing an enriching experience for ELL students indicates a need for further reform. In a grounded theory study, Johnson (2013) coined the term "educational turbulence" when describing science education reform, since interactions between business and politics on federal and district levels impact all aspects of the system. The systematic reforms that are needed to improve student outcomes "plays out within the context of local (and national) educational policy and realities such as resource allocation, mandated assessments, values, and stakeholder expectations" (Johnson, Bolshakova, \& Waldron, 2016, p. 478). Drawing specific focus on science teachers of students who are acquiring English as a second language, research findings suggest there are numerous challenges faced by teachers, however only two of the major challenges will be addressed in this research article. The first challenge concerns methods in which science activities can be restructured to reduce the language load required for participation but maintain the rigor of the science content and processes (Lee \& Buxton, 2013). The second challenge concerns the science teacher's struggle with enacting culturally responsive pedagogies (CRP) (Brown \& Crippen, 2016). In order to address these challenges, the Canadian Teacher's Federation (2011) recognizes the importance of understanding and reviewing the relevant underlying conceptual developments and theoretical frameworks.

\section{First Challenge Faced by Teachers: modifying materials for the ELL}

Addressing the two chosen ELL science teacher challenges of interest, the first of which identifies the struggle to modify science curriculum while maintains its rigor; inquirybased solutions are centered around simplifying the language and enabling students to obtain a more general understanding of the content, a reductionist approach is often employed in these strategy plans (Abd-El-Khalick et al., 2003). Reductionism in curriculum can be viewed in three specific formats: methodological, ontological, and epistemological (Allen, 1991). The methodological reductionism involves separating a big idea into smaller divisible parts, studying them independently and building the understanding back to a now understandable whole, while epistemological and ontological reductionism address the NOS and what is measured as reality in its essence (Allen, 1991). Reductionism manifested throughout the educational system, from stating goals and outcomes that are simplified to a bare-minimum to teaching science subjects as separate entities (Allen, 1991). Beyond this reductionism, professional development opportunities, specifically summer institutes and short programs offered as professional development for teachers and working professionals, the BC Teachers' Federation (2016) describes them mostly as a series of strategies and methodologies. Additional supports are offered in the form of inclusive classroom instruction, with the presence of an ELL specialist, and when focusing on the science classroom, supports are in the form of inquiry-based learning or sheltered instruction (BC Ministry of Education, 2017). When reviewing the inclusive classroom design, teachers are to follow a few steps to achieve this; they must observe how their students engage and interact with one another, create a cooperative seating-plan for their students, and apply cooperative 
learning strategies amongst their students (Jones \& Sterling, 2011). To allow for a fruitful observation of student engagement, it is recommended that the teachers spend one week on this process while providing students with icebreakers and other review activities (Jones \& Sterling, 2011). In the second step, which is also deemed as the most important step, the teacher is encouraged to set up the classroom environment (if possible) in quartets, to strategically place students with peers who express characteristics opposite to their own (i.e. talkative with quiet, higher-performing with lower...etc.), this is believed to optimize the classroom learning environment (Jones \& Sterling, 2011). In the final step, a number of cooperative learning strategies are described including Round-Robin-A game in which students answer questions sequentially, peer coaching, and using white boards for various learning purposes (Jones \& Sterling, 2011). The British Columbia Teachers' Federation (2016) encourages an inclusive classroom design to best address the needs of the students, but acknowledge the need to modify materials, request education assistance, and provide appropriate learning strategies on part of the classroom teacher.

Alternatively, the supports in place for science classrooms contrast one another and the teacher is to choose their preferences with the flexible nature of the curriculum. In an inquiry-based model, the teacher would refrain from using the science words or vocabulary at the onset of the lesson, and would focus more on showing students materials, activities, or demos, that they will analyze in their discussions and arrive at a sufficient explanation and understanding of the phenomena within the lesson (Settlage, Madsen, \& Rustad, 2005). Studies revealed challenges for ELL students in this model specifically when inquiry-based science assessments required them to use English in communicating their understanding; their limited language proficiency cause these assessments to be uninformative, as a result it is recommended they have the opportunity to demonstrate their learning in alternative formats whether in writing, orally, through drawings and creating tables and graphs (Turkan \& Liu, 2012). Using a somewhat reverse and more prescriptive design, the sheltered instruction approach emphasizes using clear content and language goals at the onset of the science lesson (Echevarria, Vogt, \& Short, 2017). Studies comparing inquiry-based classroom models with that of Sheltered Instruction found the latter model was not sufficient enough to teach science concepts to the ELL and researchers had to resort to a more modified version of this model, Sheltered Instruction Observation Protocol (Settlage, Madsen, \& Rustad, 2005). This model was developed to enable teachers "to integrate content and language instruction for students learning through a new language" (Echevarria, Vogt, \& Short, 2017, p.17). This specific model also provides ELL teachers with a thirty-item checklist that is centered on providing content and language instruction, scaffolding techniques, and differentiated instruction in multi-level classrooms (Echevarria, Vogt, \& Short, 2017).

\section{Second Challenge Faced by Teachers: integrating student culture in the curriculum}

The aforementioned inquiry-based designs also provide numerous opportunities for teachers to connect with their students and their cultural backgrounds along with the culture of science, though it is acknowledged that much research and 
preparation is due on the teachers' part to successfully implement this model in the classroom (Settlage, Madsen \& Rustad, 2005). As student populations increased in diversity, teachers recognized a growing disparity in ELL and nonELL student achievements in the science, technology, engineering, and mathematics (STEM) content areas (Brown \& Crippen, 2016). As a result of this trend, studies initiated on the student populations unraveled the mystery and attributed much of this widening gap to the disconnect between what students are learning and their personal and social lives; a cultural disconnect relevant to their academic achievement and development (Buxton, Lee, \& Santau, 2008). As a shared understanding, the personal and social aspect of development is conceded as a core competency within the BC Curriculum (BC Ministry of Education, 2017). The personal and social competency involves the recognition of "cultural knowledge, prior experience, frames of reference, and performance styles," to directly and indirectly strengthen academic performance of diverse students (Brown \& Crippen, 2016; Gay, 2010, p.31). Researchers directing their attention towards the sociocultural challenges faced by teachers, and achievement disparity between ELL and non-ELL students, developed a Culturally Responsive Pedagogy (CRP) that is specific to integrating the student into the curriculum and engaging them to overcome much of the sociocultural challenge (Brown \& Crippen, 2016). Presented in the form of a CRP toolbox, the design intends to provide science teachers with culturally informed science topics and frames of reference that are believed to be relevant to student backgrounds, lives and experiences (Brown \& Crippen, 2016). The BCTF offers educators workshops that relay components of a culturally responsive pedagogy, and acknowledge the importance of diversity, adapted from Professor Geneva Gay's (2000) work on educator awareness of sociocultural dynamics in the classroom (BCTF, 2017; Kozelski, n. d.; Ladson-Billings, 1995). The scarcity of research models formed to address this challenge is attributed to the nature of Western systems; its neoliberal, individualized approaches to success and direct connections to financial gain (Sleeter, 2012). The emergence of a direct and deliberate connection between the fields of education and business are not unforeseen, rather it has been a topic of discussion for decades. In their article on The Cult of Citizenship Education, Alan Sears and Emery Hyslop-Margison (2006) demonstrate how the political discourse often leads to educational reform and how the meaning of citizenship is influenced by the contributions individuals are able to add to the system. Reviewing the International Student Recruitment: Policies and Developments in Selected Countries, Becker and Kolster (2012) relate the increasing global integration of international students into broader forms of the higher cooperation, to the economic and political power shifts in the East. A downward mobility in the West and an upward mobility in the East compares population dynamics of age, birthrates, graduates, and workforce costs. This reveals old and declining Western populations, below replacement birthrates, scarcity of the 'right' graduates, and high workforce costs; opposites of the case in the East (Holmes, 2008). In his book, Kemal Guruz (2011) reveals the effects that higher fees paid by international students have on the global education market, he states trades take place in the following services and products: 
(1) Education-related publishing, (2) educational equipment and course material, (3) consultancy services provided to ministries and companies, (4) guidance counseling, and placement services provided to students, (5) preparatory teaching, especially teaching of English as a foreign language, and (6) testing (p.146).

This globalization is seen as central to the world of finance and trade, communications, and information technologies; with governments becoming more national in form, education is becoming more central to government, enabling "issues of identity and difference [to] become more important in the politics of education" (Marginson, 2010).

Researchers Cory Buxton, Okhee Lee, and Alexandra Santau (2008) explored reasons for the diminishing number of professional development opportunities that implement ELL cultural perspectives and created a "six-category taxonomy" of the challenges. Buxton, Lee, and Santau (2008) summarize each category revealing a set of difficulties teachers face due to their own perceptions of student diversity, difficulties related to time constraints in efforts to engage students with science concepts and their cultural backgrounds, difficulties in producing culturally relevant curriculum materials and other difficulties related to assessment and assessment outcomes of these students.

The BC Ministry of Education Teacher Regulation Branch (TRB) (2012) lists eight standards directed at teachers to further amplify their roles and responsibilities:

1. Educators value and care for all students and act in their best interests.

2. Educators are role models who act ethically and honestly.

3. Educators understand and apply knowledge of student growth and development.

4. Educators value the involvement and support of parents, guardians, families and communities in schools.

5. Educators implement effective practices in areas of classroom management, planning, instruction, assessment, evaluation and reporting.

6. Educators have a broad knowledge base and understand the subject areas they teach.

7. Educators engage in career-long learning.

8. Educators contribute to the profession.

(Ministry of Ed., 2012, p.4)

In line with the similar professional development goals in teacher preparatory programs, these standards promote and encourage teachers to continue in their journeys of personal professional development, implement the changes they view necessary in their own classrooms and with their own student population, and 
prepare to alter their plans each year (Clark \& Clark, 2002). Likewise, under the School Act (168.), the BCTF (2017) emphasizes the importance of assessing their ELL students each year to determine their eligibility for any additional supports.

\section{Exploring Workshops Offered as Professional Development}

In supporting teachers of ELLs, the British Columbia Teacher's Federation (BCTF) currently offers one workshop that aims to educate participants about useful strategies in an inclusive classroom, while another offered workshop is designed around cultural awareness. Mostly available as links online, the BCTF emphasizes the workshops explain content and materials already available on their website (BCTF, 2017). Despite success rates in using "authentic visuals, hands-on activities, and cooperative learning" as modes of instruction, feminist action research found many students experienced feelings of being overwhelmed, panic, confusion, and apprehension towards engagement in the hands-on activities when working in groups (Buck, Mast, Ehlers, \& Franklin, 2005, p.1028). Other longitudinal studies revealed teachers who have a deeper understanding of curriculum theorists and their approaches to content based knowledge strategies, are more influential in developing conceptual understanding in their students when using classroom activities and strategies, as well as more likely to maximize their own professional learning and development (Cheng, Tang, \& Cheng, 2012). Options to further maximize professional learning experiences are offered through specific postsecondary institutions in the Lower Mainland (e.g. University of British Columbia, Simon Fraser University...etc.). The University of British Columbia (UBC) delivers professional development opportunities for teachers and working professionals in the form of online courses that are flexible and can fit into a busy schedule, off-campus faceto-face courses where on-site professional development is delivered, summer institutes that are built-in short programs that typically span two-weeks, and conferences that are delivered across the globe in efforts to bring expertise from multiple perspectives and backgrounds together (UBC, 2017).

Analyzing the BC Ministry of Education's approach to addressing the gaps and disconnect within the system, external workshops that are provided and sponsored, are offered through school districts and are contingent on the teachers ability to attend and have sufficient funding for replacement teachers (BCTF, 2017). The summer institutes, two-week programs, enable working professionals to acquire skills, tools, and strategies without the need to give up classroom instruction time (UBC, 2017). The Sheltered Instruction Observation Protocol (SIOP) model is relayed through a four-day intensive workshop usually held at the end of the school year (SIOP, 2017). This workshop provides teachers with an understanding of the importance of mediating concepts through the use of students' L1; it provides a vast plethora of classroom strategies and suggests numerous ways of differentiating instruction (Echevarria, Vogt, \& Short, 2017). As a distinguishing feature of the SIOP model, the learners L1 and L2 abilities are assessed and addressed through Cummins (1983) work on BICS and CALP (Echevarria, Vogt, \& Short, 2017). The BC Ministry of Education also acknowledges the language learner's proficiency in English on a basic interpersonal level and on an academic level (BC Ministry of Education, 2016). Corresponding with the reality of increased number of ELL students accessing the system and the shortage of teachers trained in such a 
context, SIOP was developed to bridge the gap between teachers, ELL students, and a system in reform (SIOP, 2017). Meeting the core competencies of the BC Curriculum: communication, thinking, personal and social, this model incorporates a "high level of student engagement and interaction with the teacher, with other students, and with text" which is believe to lead to elaborated discourse and critical thinking (Echevarria, Vogt, \& Short, 2017, p.21).

The above review of the literature revealed information regarding the science curriculum, expectations and core competencies of BC's New Curriculum, challenges faced by students and teachers, as well as support systems in place to address these challenges. In the following section, theoretical frameworks aimed to explain the challenges faced by the ELL science students are compiled to ultimately support a proposition for a slightly new possible program that can assist teachers, students and schools in tackling some of their biggest concerns.

\section{Discussion}

Exploring the concept of cognitive implications of language development from a Vygotskian perspective, the learner's language capacity provides them with auxiliary tools necessary to solve complex tasks, overcome impulsive action, to intuitively plan ahead, and to master their own behavior (Vygotsky, 1978). Vygotsky's views a learner's interaction with complex situations inductive of auxiliary stimuli that enable them to cope and adapt to the demands in context; these stimuli are influenced by the learner's culture, their language capacity, thought process and personality (Vygotsky, 1978). Studying the association between thought and language, Vygotsky (1978) references K. Buhler's principle on the precedence of technical thinking, which comprises the onset of cognitive development, to intelligent speech (Vygotsky, 1978). Also viewed as the internalization of speech, a learner must undergo a series of transformations for a successful process of internalization: visuals and other external operations are reconstructed in the learner's mind and begin to form internally, interpersonal processes are transformed into intrapersonal ones-these are concerning the cultural development relative to the culture of the environment the learner is immersed in-and the undergoing of developmental processes that are reflected in the individual's conceptualization of themselves and their own personalities (Vygotsky, 1978). In his cultural-historical activity theory (CHAT), Vygotsky believed higher-level systemic mental processes have their origins in lower, more spontaneous forms (Shotter, 2006). These spontaneous forms include sociocultural signs and structures (i.e. language and verbal communication), which enable us to reach the higher levels of understanding (Shotter, 2006). It is through ones ability to utilize higher-level language that they will be able to expand their mental capacity, cultural artifacts are tools that aid with this process with mediation (Cole \& Gajdamaschko, 2007). In mediating concepts to the ELL, the advantage one would have can be seen in the student's ability to learn the language, draw the connections with their own understandings (Jonassen \& RohrerMurphy, 1999). The learners' mediated experiences are inclusive of their own cultural artifacts, it is important to note that these are not physical structures or objects, rather they are a compilation of objects and people, understandings generated over the course of history, it is the development of meaning through a medium (Cole \& Gajdamaschko, 
2007). In the case of the language learner, they may have already formulated ideas and definitions through their own cultural experiences, it is my understanding that a Vygotskyan perspective would use their inner language, dialectic, and dialogic processes to ensure they can further expand their scope of knowledge.

Further expanding on the ELL student in this work, their prospects in acquiring language and content conceptual development are higher when they are more academically capable in their native first languages (Cummins, 1983). Consequently, when acquiring English as a second language, their conceptually-developed abilities in their first language would enable them to bridge the gaps between their thought processes and the instruction they receive (Cummins, 1983). Cummins (1983) depicted a dual iceberg model to explain the ELL student's basic and academic language development: the more visible and apparent basic interpersonal communication skills (BICS) are noted to generally develop over a shorter period of time compared to the invisible and more complex language processes involving cognitive academic language proficiency (CALP) (Roessingh, 2006). The "interpersonal" and social process is emphasized yet again in the literature, more relevantly Vygotsky "views learning as a profoundly social process [that] emphasizes dialogue and the varied roles that language plays in instruction and in mediated cognitive growth" (Vygotsky, 1978, p.131). Studies on Vygotskian applications in the science classroom reveal three implications for instruction within this framework: communicative, cognitive, and socioculturalconstructivist (Howe, 1996). In the communicative phase, learners are viewed as participants in "a joint enterprise" where meaning is derived via interactions with others and mediation through language (Howe, 1996, p. 45). The second implication of cognitive development is associated with the context of science instruction; cognitive demand and complexity of a task is not independent of the context of the learner (Howe, 1996). The third implication recognizes the conception of science knowledge acquisition in relation to the interpersonal interactions formed by the learner (Howe, 1996). It is noteworthy to recognize much of these implications closely resemble the core competencies of BC's New Curriculum, thus, understanding this perspective is key to developing an effective program that addresses the ELL in the science context as well as aiding the teacher in overcoming challenges related to language and sociocultural developments, as mentioned previously in this research article (Burton, 2013).

Another conceptual framework of interest is that of Ralph Tyler (1967), in his objectivesbased approach, he shares his views of a systematically functioning and constructively designed science classroom (Tyler, 1967). Tyler appraised multiple science classrooms and reviewed research on their designs, he noted in his work how many science educators resort to varied their strategies of instruction without sufficient content knowledge (Tyler, 1967). He reported that strategies used in the same courses differed enough to alter objective and methodologies, causing difficulty to compare assessments; Tyler also notes how this notion is one that is difficult to report due to the negative connotations it may incur (Tyler, 1967). The model he promotes for a science classroom, is structured with clear objectives, methods, materials, and outcomes, Tyler also emphasizes the fluidity in this model when formulating it, the context of the learner and their degree of motivation must also be accounted for and considered (Tyler, 1967). 
Cognizant of context and motivation with object-orientedness, activity theory is a "philosophical framework for studying different forms of human praxis as developmental processes, both individual and social levels interlinked at the same time" (Jonassen \& Rohrer-Murphy, 1999, p. 62). In this view, activity and consciousness are connected and interrelated, it is not a set of strategies or methodologies, rather it is a framework that evolves with the learner and the content, the activity, action and operation, the motive, goal and conditions (Jonassen \& Rohrer-Murphy, 1999). More holistically, CHAT employs a number of assumptions that enable it to form a cohesive understanding regarding the learner: the context and connection to the mind, the learner's consciousness of the world, intentionality in actions, goal-oriented activities, benefit to communities, and the cultural historic dimensions (Jonassen \& RohrerMurphy, 1999). Essentially, each assumption is summarized as follows: the interrelated connection between mind and context is built on the understanding that an individual's perceptions are highly influenced by their interactions within their environment, consciousness is perceived as "intention, memory, reasoning, and speech...[it] is manifested in practice" which is embedded in society and composed of people and artifacts, the intentionality emerges from "contradictions that individuals perceive in their environments", it is their perceptions while the goals they set forth provide them with the affordances for activity (Jonassen \& Rohrer-Murphy, 1999, p. 65). With the sociocultural and cultural-historical dimensions, the tools for mediation are formulated through collaboration, interactions with community, and adherence to the rules within society (Jonassen \& Rohrer-Murphy, 1999).

The cultural- historical activity theory (CHAT) draws a thread of connection between previous frameworks and the influence it may hold on the creation of a program that embeds its perspective, as opposed to a relay of a multitude of strategies without the explanation of their praxes. The proposed program to face the challenges of the ELL Science teacher in the Lower Mainland would be structured similar to the Tylerian objectives-based model, the objectives of this program would entail the attendees be briefed on the appropriate theoretical frameworks that are employed, the importance of internalizing the process before using any set of strategies while being explicit in communicating their intentions to students (i.e. students will be asked seek what motivates them), the sociocultural aspect of this phenomena would be translated through a collaborative workshop design, theoretical frameworks will explicitly be reviewed with each strategy that is mentioned so as to provide teachers with multiple ingredients which they will use based on their context, the context of their learners and the level of motivation they may have during that time. This is different from other programs that are more prescriptive by nature; SIOP, includes a list of thirty-item toolboxes that a teachers' lesson plan should best follow (Echevarria, Vogt, \& Short, 2017). The proposed program intends to educate teachers about their chosen classroom strategies beyond simple descriptive procedures, it enables educators to recognize process behind procedure and focuses on strategy comprehension and contexts of use.

\section{Conclusion}

Based in the Lower Mainland, British Columbia, and specific to teachers of English Language Learners in the science classroom, this research article intended to design and 
propose a program that will enable such teachers to face two major challenges they reported having; their struggles to implement and modify activities to the needs of this student demographic, and the challenges in creating a culturally responsive pedagogy. From recognizing the importance of speech and language on thought processes, to acknowledging the importance of language awareness and development on the social and academic levels, to the creation of systemic science courses that are reflective by nature, this research article united these divided parts to yield a more cohesive whole; a program that teachers can rely on and use to their benefit. While other programs are simple relays of strategies and standards with no evidence of theoretical frameworks, as revealed in the research throughout this article. The unique feature of the program I propose encompasses its deep consideration for the value of educational theorists and the wealth of knowledge they bring to the profession. 


\section{References}

Abd-El-Khalick, F., Bell, R. L., \& Lederman, N. G. (1998). The Nature of Science and Instructional Practice: Making the Unnatural Natural. Science Education, 82(4), 417-36.

Abd-El-Khalick, F., BouJaoude, S., Duschl, R., Lederman, N., Mamlok-Naaman, R., Hofstein, A., Niaz, M., Treagust, D., Tuan, H. (2004). Inquiry in science education: International perspectives. Science Education, 88(3), 397-419.

Allen, R. T. (1991). Reductionism in Education. Paideusis, 5(1). 20-35.

BC Curriculum. (2017). Curriculum Overview. Retrieved from https://www.curriculum.gov.bc.ca/curriculum/overview

BC Ministry of Education (2016). 2014/15-2016-17 Annual Service Plan Report 2017/18. Victoria: British Columbia.

BC Ministry of Education. (January 2017). FACTSHEET: International students in B.C. Retrieved from: https://news.gov.bc.ca/09052

BC Ministry of Education. (2012). Standards for the Education, Competence \& Professional Conduct of Educators in British Columbia (4 $4^{\text {th }} \mathrm{ed}$.) [Victoria, B.C.]: Ministry of Education.

BCTF. (2012). 2012 BC Education Facts. Retrieved from http://www.bctf.ca/uploadedfiles/public/publications/2012edfacts.pdf

BCTF. (2016). The Practice of Teaching: A Handbook for New Teachers and TTOCs. Retrieved from http://www.bctf.ca/NewTeachersHandbook/

Becker, R., \& Kolster, R. (2012). International student recruitment policies and developments in selected countries. Netherlands Organisation for International Cooperation in Higher Education. The Hague: Nuffic.

Brown, J., \& Crippen, K. (2017). The Knowledge and Practices of High School Science Teachers in Pursuit of Cultural Responsiveness. Science Education, 101(1), 99133 .

Buck, G., Mast, C., Ehlers, N., \& Franklin, E. (2005). Preparing teachers to create a mainstream science classroom conducive to the needs of English-language learners: A feminist action research project. Journal of Research in Science Teaching, 42(9), 1013-1031

Bunch, G. C. (2010). Preparing mainstream secondary content-area teachers to facilitate English language learners' development of academic language. In C. Faltis \& G. Valdés (Eds.), Education, immigrant students, refugee students, and English learners (Yearbook of the National Society for the Study of Education; Volume 
109, Issue 2, pp. 352-383). New York, NY: Columbia University Press.ELLSC. (2001). English as a Second Language: Standards. National Library of Canada Cataloguing in Publication Data. Ministry of Education, British Columbia.

Burton, E. P. (2013). Student Work Products as a Teaching Tool for Nature of Science Pedagogical Knowledge: A Professional Development Project with In-Service Secondary Science Teachers. Teaching and Teacher Education: An International Journal of Research and Studies, 29, 156-166.

Buxton, C., Okhee, L., \& Santau, A. (2008). Promoting Science among English Language Learners: Professional Development for Today's Culturally and Linguistically Diverse Classrooms. Journal of Science Teacher Education, 19(5), 495-511.

Buxton, C. A., Allexsaht-Snider, M., Suriel, R., Kayumova, S., Choi, Y., Bouton, B., \& Baker, M. (2013). Using Educative Assessments to Support Science Teaching for Middle School English-Language Learners. Journal of Science Teacher Education, 24(2), 347-366.

Canadian Teachers' Federation (2011). The Voice of Canadian Teachers on Teaching and Learning. Ottawa.

Casale, R. (2004). The educational theorists, the teachers, and their history of education. Studies in Philosophy and Education, 23(5), 393-408.

Chamot, A., \& O'Malley, J. (1996). The Cognitive Academic Language Learning Approach: A Model for Linguistically Diverse Classrooms. The Elementary School Journal, 96(3), 259-273.

Cheng, May M. H., Tang, Sylvia Y. F., \& Cheng, Annie Y. N. (2012). Practicalising Theoretical Knowledge in Student Teachers' Professional Learning in Initial Teacher Education. Teaching and Teacher Education: An International Journal of Research and Studies, 28(6), 781-790.

Cho, Seonhee, \& McDonnough, Jacqueline T. (2009). Meeting the Needs of High School Science Teachers in English Language Learner Instruction. Journal of Science Teacher Education, 2O(4), 385-402.

Clark, J. A., \& Clark, J. A. (2002). A guide to school legislation in British Columbia. Vancouver, BC: British Columbia School Trustees Association.

Cole, M., \& Gajdamaschko, N. (2007). Vygotsky and Culture. In Daniels, H., Cole, M., \& Wertsch, J. V. (2007). The Cambridge companion to Vygotsky. (Ed.). Choice Reviews Online, (pp.193-211).

Cummins, J. (1983). Bilingualism and Special Education: Program and Pedagogical Issues. Learning Disability Quarterly, 6(4), 373-86. 
Cummins, J. (1983). Language Proficiency, Biliteracy and French Immersion. Canadian Journal of Education / Revue Canadienne De L'éducation, 8(2), 117-138.

Echevarria, J., Vogt, M., \& Short, D. J. (2017). Making Content Comprehensible for English Learners: The SIOP Model. ( $5^{\text {th }}$ ed.). USA: Pearson Education Inc.

ELL. (2001). English as a Second Language: Standards. National Library of Canada Cataloguing in Publication Data. Ministry of Education, British Columbia.

ELL. (2013). English Language Learning Policy and Guidelines. Retrieved from http://www2.gov.bc.ca/assets/gov/education/administration/kindergarten-tograde-12/english-language-learners/guidelines.pdf

Fang, Z. (2006). The language demands of science reading in middle school. International Journal of Science Education, 28(5), 491-520

Gay, G. (2010). Culturally responsive teaching: Theory, research, and practice (2nd ed.). New York, NY: Teachers College Press

Guruz, K. (2011). Higher Education and International Student Mobility in the Global Knowledge Economy. Albany, US: SUNY Press. Retrieved from http://www.ebrary.com.proxy.lib.sfu.ca

Han, H., \& Cheng, L. (2011). Tracking the Success of English Language Learners within the Context of the Ontario Secondary School Literacy Test. Canadian and International Education, 4O(1), 76.

Holmes, A., \& Taylor \& Francis eBooks. (2008). Commoditization and the strategic response. Burlington, VT;Aldershot, England;: Gower.

Howe, A. C. (1996). Development of Science Concepts within a Vygotskian Framework. Science Education, 8o(1), 35-51.

Johnson C. C. (2013). Educational turbulence: The influence of macro and micro policy on science education reform. Journal of Science Teacher Education, 24, 693-715

Johnson, C. C., Bolshakova, V. L. J., \& Waldron, T. (2016). When Good Intentions and Reality Meet: Large-Scale Reform of Science Teaching in Urban Schools With Predominantly Latino ELL Students. Urban Education. 51(5). 476-513.

Jonassen, David H., \& Rohrer-Murphy, Lucia. (1999). Activity Theory as a Framework For Designing Constructivist Learning Environments. Educational Technology Research and Development, 47(1), 61-79.

Jones, T., \& Sterling, D. R. (2011). Cooperative Learning in an Inclusive Science Classroom. Science Scope, 35(3), 24-28. 
Kozelski, E. B. (n.d.). Culturally Responsive Teaching Matters!. Equity Alliance. Retrieved from http://www.equityallianceatasu.org/sites/default/files/Website files/Culturally ResponsiveTeaching-Matters.pdf

Kuehn, L. (2016). New Curriculum in Science and Social Studies-Notes from the Inside. Retrieved from http://www.bctf.ca/uploadedFiles/Public/Issues/CurriculumSeminarReport201 4-04-16.pdf

Ladson-Billings, G. (1995). Toward a Theory of Culturally Relevant Pedagogy. American Educational Research Journal, 32(3), 465-91.

Lee, O. (1997). Teacher Professional Development to Improve Science and Literacy Achievement of English Language Learners. Theory into Practice., (2), 117.

Lee, O., \& Buxton, C. (2013). Integrating Science And English Proficiency For English Language Learners. Theory Into Practice, 52(1), 36-42.

Lucas, T., Villegas, A. M., \& Freedson-Gonzalez, M. F. (2008). Linguistically responsive teacher education: Preparing teachers to teach English language learners. Journal of Teacher Education, 59, 361-373

Manavathu. M. \& Zhou, G. (2012) The Impact of Differentiated Instructional Materials on English Language Learner (ELL) Students' Comprehension of Science Laboratory Tasks, Canadian Journal of Science, Mathematics and Technology Education, 12(4), 334-349

Marginson, S. (2010). After globalization: emerging politics of education. Journal of Education Policy, 14(1). p.19-31.

Mollaei, F. \& Rahnama, H. (2012). Experiential Education Contributing to Langauge Learning. International Journal of Humanities and Social Sciences. Center for Promoting Ideas. USA. 2(21), pp. 268-279.

Roekel, D. V. (2008). English language learners face unique challenges. Retrieved from http://www.nea.org/assets/docs/HE/ELL Policy Brief Fall 08 (2).pdf

Roessingh, H. (2006). BICS-CALP: An Introduction for Some, a Review for Others. TESL Canada Journal, 23(2), 91-96.

Roessingh, H., Kover, P., \& Watt, D. (2005). Developing Cognitive Academic Language Proficiency: The Journey. TESL Canada Journal, 23(1), 1-27.

School Act (2016). School Act: Revised Statutes of BC. Retrieved from www.bced.gov.bc.ca/legislation/schoollaw/revisedstatutescontents.pdf 
Sears, A. M.; Hyslop-Margison, E. J. (2006). The Cult of Citizenship Education. Troubling Places for Citizenship Education. (pp.13-24). New York, Peter Lang. Pub.

Settlage, J., Madsen, A., \& Rustad, K. (2005). Inquiry Science, Sheltered Instruction, and English Language Learners: Conflicting Pedagogies in Highly Diverse Classrooms. Issues in Teacher Education, 14(1), 39-57.

Shapiro, S. (2014). "words that you said got bigger": English language learners' lived experiences of deficit discourse. Research in the Teaching of English, 48(4), 386.

Short, D. J., Fidelman, C. G., \& Louguit, M. (2012). Developing Academic Language in English Language Learners through Sheltered Instruction. TESOL Quarterly: A Journal for Teachers of English to Speakers of Other Languages and of Standard English as a Second Dialect, 46(2), 334-361.

Shotter, J. (2006). Vygotsky and Consciousness as Con-scientia , as Witnessable Knowing Along with Others. Theory \& Psychology, 16(1), 13-36.

SIOP. (2016). Helping Educators Work Effectively with English Language Learners. Retrieved from http://www.cal.org/siop/resources/

Sleeter, C. E. (2012). Confronting the Marginalization of Culturally Responsive Pedagogy. Urban Education, 47(3), 562-584.

Turkan, Sultan, \& Liu, Ou Lydia. (2012). Differential Performance by English Language Learners on an Inquiry-Based Science Assessment. International Journal of Science Education, 34(15), 2343-2369.

Tyler, R. (1967). Analysis of strengths and weaknesses in current research in science education. Journal of Research in Science Teaching, 5(1), 52-63.

Verdugo, Richard R., \& Flores, Brittney. (2007). English-Language Learners: Key Issues. Education and Urban Society, 39(2), 167-193.

Vygotsky, L. S. (1978). Mind in society: The development of higher psychological processes. Cambridge: Harvard University Press. ISBN:0-674-57629-2.

Webster, M. (2017). Retrieved June 5, 2017, from https://www.merriamwebster.com/dictionary/charge 